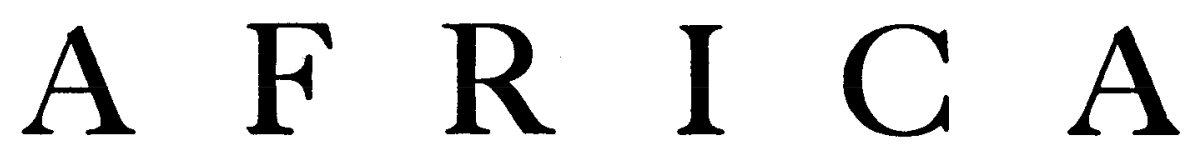

JOURNAL OF THE INTERNATIONAL AFRICAN INSTTTUTE

\title{
OBITUARY
}

\section{HAROLD GODFREY JUDD, C.B.E.}

Ir is with deep regret that we have to record the death, on s January 1961 , of Mr. Harold Godfrey Judd, a Life Member of the Institute and for many years its Honorary Treasurer.

Mr. Judd's connexion with the Institute began in 1926 when his firm, Messrs. Mann, Judd, Gordon \& Co., offered its services to the recently formed organization as honorary accountants. Mr. Judd also acted for many years as one of the Institute's Trustees, and advised on many aspects of its financial organization. On the death of Sir Humphrey Leggett in 1944, he accepted the Executive Council's invitation to become Honorary Treasurer, and for the next eleven years the Institute was fortunate enough to have the help and guidance of one who not only was already well acquainted with its affairs, but whose lifetime of wide administrative and professional experience was of the greatest value. His expert opinion, whether on important questions of financial policy or on matters of office routine, was frequently sought and always freely given, despite the many other commitments of a full and active life.

A man of great charm and affability, he will be remembered with gratitude and affection by the many members of the Council who came to know him well, as well as those members of the Institute's staff who relied so greatly on his kindly advice and interest.

We feel sure that all who knew him will join us in extending our deepest sympathy to Mrs. Judd and members of her family in their loss.

DARYLL Forde

'Africa', the Journal of the International African Institute, is published by the Institute, but except where otherwise stated the writers of the articles are responsible for the opinions expressed. 